\title{
Operator Linear-2 Terbatas pada Ruang Bernorma-2 Non-Archimedean
}

\author{
Burhanudin Arif Nurnugroho', Supama², A. Zulijanto \\ 1 Program Studi Pendididkan Matematika, Fakultas Keguruan dan IImu Pendidikan, \\ Universitas Ahmad Dahlan, Yogyakarta, Indonesia. \\ 2Jurusan Matematika, Fakultas Matematika dan IImu Pengatahuan Alam, \\ Universitas Gadjah Mada, Yogyakarta, Indonesia.
}

Korespondensi; Burhanudin Arif Nurnugroho, Email: burhanudin@pmat.uad.ac.id

\begin{abstract}
Abstrak
Di dalam paper ini dikonstruksikan operator linear-2 terbatas dari $X^{2}$ ke $Y$, dengan $X$ ruang bernorma-2 non-Archimedean dan $Y$ ruang bernorma non-Archimedean. Di dalam paper ini ditunjukan bahwa himpunan semua operator linear-2 terbatas dari $X^{2}$ ke $Y$, ditulis $B\left(X^{2}, Y\right)$ merupakan ruang bernorma non-Archimedean. Selanjutnya, ditunjukan bahwa $B\left(X^{2}, Y\right)$, apabila $Y$ ruang Banach non-Archimedean.
\end{abstract}

Kata Kunci: norma; ruang operator; terbatas; linear-2; bernorma-2 non-Archimedean

\begin{abstract}
In this paper we construct bounded 2-linear operators from $X^{2}$ to $Y$, where $X$ is non-Archimedean 2-normed spaces and $Y$ is a non-Archimedean-normed space. We prove that the set of all bounded 2-linear operators from $X^{2}$ to $Y$, denoted by $B\left(X^{2}, Y\right)$ is a non-Archimedean normed spaces. Furthermore, we show that $B\left(X^{2}, Y\right)$, is a nonArchimedean Banach normed space, whenever $Y$ is a non-Archimedean Banach space.
\end{abstract}

Keywords: Norm; operator spaces; bounded; 2-linear; non-Archimedean 2-normed

\section{Pendahuluan}

Konsep norma dan operator linear memiliki peranan penting dalam analisis fungsional. Mencari konsep yang merupakan pengembangan dari konsep norma, kemudian meneliti konsep operator linear yang berkaitan merupakan salah satu topik penelitian dalam analisis fungsional. Beberapa penelitian mengenai pengembangan konsep norma salah satunya adalah konsep norma non-Archimedean [7,8,9]. Lebih lanjut mengikuti konsep norma-2, yang diperkenalkan oleh Gahler [1,2], konsep norma nonArchimedean dikembangkan menjadi konsep norma-2 non-Archimedean $[5,10,11,12]$.

Di dalam [9], telah dijelaskan mengenai konsep operator linear pada ruang bernorma nonArchimedean. Selanjutnya, pada $[3,4,6]$ telah dibahas mengenai operator linear-2 (operator linear-n) pada ruang bernorma-2 (bernorma-n).

Di dalam paper ini akan dibahas mengenai konstruksi ruang operator linear-2 terbatas pada ruang bernorma-2 non-Archimedean. Selanjutnya, akan dibuktikan bahwa $B\left(X^{2}, Y\right)$, yaitu koleksi semua operator linear-2 terbatas dari $X^{2}$ ke $Y$, merupakan ruang bernorma-2 non-Archimdean. Apabila $Y$ ruang Banach non-Archimedean maka $B\left(X^{2}, Y\right)$ juga merupakan ruang Banach non-Archimedean.

\section{Landasan Teori}

Penelitian dilakukan dengan terlebih dahulu mengkonstruksikan ruang operator linear-2 terbatas pada ruang bernorma-2 non-Archimedean. Selanjutnya, akan dicari suatu fungsi yang merupakan norma dari ruang tersebut. 
Berikut diberikan beberapa konsep yang mendasari penelitian ini. Konsep nilai mutlak pada $\mathbb{R}$, diperumum pada sebarang lapangan $\mathbb{K}$. Berikut diberikan beberapa konsep tentang konsep nilai mutlak pada sebarang lapangan $\mathbb{K}[13]$.

Definisi 1. Diberikan sebarang lapangan $\mathbb{K}$. Nilai mutlak pada $\mathbb{K}$ didefinisikan sebagai fungsi $||:. \mathbb{K} \rightarrow$ $\mathbb{R}$, yang memenuhi kondisi-kondisi berikut:

i. $|x| \geq 0, \forall x \in \mathbb{K}$,

ii. $|x|=0$ jika dan hanya jika $x=0_{\mathbb{K}}$,

iii. $|x y|=|x||y|, \forall x, y \in \mathbb{K}$,

iv. $|x+y| \leq|x|+|y|, \forall x, y \in \mathbb{K}$.

Pasangan ( $\mathbb{K},|$.$| ) disebut lapangan bernilai.$

Nilai mutlak $|$.$| pada \mathbb{K}$ dikatakan non-Archimedean jika himpunan $\left\{n .1_{\mathbb{K}}: n \in \mathbb{N}\right\}$ terbatas, dalam kasus lain disebut Archimedean. Beberpa karakteristik dari nilai mutlak non-Archimedean diberikan pada teorema-teorema berikut:

Teorema 1. Diketahui lapangan bernilai $(\mathbb{K},||$.$) . Pernyataan pernyataan$

i. Nilai mutlak $\mid$.| non-Archimedean.

ii. $\left|n .1_{\mathbb{K}}\right| \leq 1, \forall n \in \mathbb{N}$.

iii. $|x+y| \leq \operatorname{maks}\{|x|,|y|\}, \forall x, y \in \mathbb{K}$.

iv. Jika $x, y \in \mathbb{K}$ dan $|x| \leq|y|$, maka $|y-x|=|y|$.

Berikut diberikan contoh lapangan bernilai non-Archimedean. Diambil sebarang bilangan prima $p$. Nilai mutlak pada $\mathbb{Q}$, didefinisikan dengan, $\left|0_{p}\right|=0$, untuk $x \in \mathbb{Z}$,

$$
|x|_{p}=p^{-r(x)}
$$

dengan $r(x)$ adalah bilangan positif terbesar sedemikian sehingga $p^{r(x)}$ membagi habis $x\left(p^{r(x)} \mid x\right)$ dan untuk setiap $x=\frac{n}{m}, n, m \in \mathbb{Z}, m \neq 0$,

$$
\left|\frac{n}{m}\right|_{p}=\frac{|n|_{p}}{|m|_{p}}
$$

Nilai mutlak $|.|_{p}$ pada $\mathbb{Q}$ tersebut selanjutnya disebut nilai mutlak $p$-adic. Untuk selanjutnya, jika tidak disebutkan secara khusus, maka nilai mutlak pada $\mathbb{Q}$ adalah nilai mutlak $p$-adic.

Dapat dimengerti bahwa untuk setiap lapangan bernilai $(\mathbb{K},||$.$) , maka fungsional d: \mathbb{K} \times \mathbb{K} \rightarrow \mathbb{R}$, dengan

$$
d(x, y)=|x-y|
$$

Merupakan metrik pada $\mathbb{K}$. Dengan demikian $(\mathbb{K}, d)$ merupakan ruang metrik. Lapangan bernilai $(\mathbb{Q},||$.$) baibukan merupangan tidak lengkap terhadap metrik d$. Selanjutnya, pelengkap dari $\mathbb{Q}$ terhadap nilai mutlak o-adic disebut himpunan bilangan $p$-adic dan dinyatakan dengan $\mathbb{Q}_{p}[9]$.

Definisi 2. Diberikan $X$ ruang linear atas lapangan bernilai non-Archimedean $(\mathbb{K},||$.$) . Fungsi \|\|:. X \times$ $X \rightarrow[0, \infty)$ dikatakan norma non-Archimedean jika

i. $\|x\|=0$ jika dan hanya jika $x=0$,

ii. $\|\alpha x\|=|\alpha|\|x\|, \forall \alpha \in \mathbb{K}, x \in X$,

iii. $\|x+y\| \leq \operatorname{maks}\{\|x\|,\|y\|\}, \forall x, y \in X$.

Pasangan $(X,\|\|$.$) disebut ruang bernorma non-Archimedean.$ 
Mengikuti konsep ruang bernorma, berikut diberikan definisi ruang bernorma-2 non-Archimedean [10].

Definisi 3. Diberikan $X$ ruang linear atas lapangan bernilai non-Archimedean $(\mathbb{K},|$.$| ), dengan dimensi$ $(X) \geq 2$. Fungsi $\|.\|:, X \times X \rightarrow[0, \infty)$ dikatakan norma non-Archimedean jika

i. $\|x, y\|=0$ jika dan hanya jika $x, y$ saling tak bebas linear,

ii. $\|x, y\|=\|y, x\|, x, y \in X$,

iii. $\|\alpha x, y\|=|\alpha|\|x, y\|, \forall \alpha \in \mathbb{K}, x, y \in X$,

iv. $\|x+y, z\| \leq \operatorname{maks}\{\|x, z\|,\|y, z\|\}, \forall x, y, z \in X$.

Pasangan $(X,\|.,\|$.$) disebut ruang bernorma-2 non-Archimedean.$

\section{Hasil dan Pembahasan}

Mengikuti konsep operator linear-2 (linear-n) terbatas $[3,4,6]$, berikut didefinisikan operator linear -2 terbatas pada ruang bernorma-2 non-Archimedean. Untuk selanjutnya $\mathrm{X}$ ruang bernorma-2 nonArchimedean dan $\mathrm{Y}$ ruang bernorma non-Archimedean atas lapangan bernilai non-Archimedean $(\mathbb{K},||$.$) .$

Definisi 4. Operator $T: X^{2} \rightarrow Y$ dikatakan linear-2 jika untuk setiap $a, b, c, d \in X$ dan $\alpha, \beta \in \mathbb{K}$ belaku

i. $T(a+c, b+d)=T(a, b)+T(a, d)+T(c, b)+T(c, d)$,

ii. $T(\alpha a, \beta b)=\alpha \beta T(a, b)$.

Definisi 5. Operator linear-2 $T: X^{2} \rightarrow Y$ dikatakan terbatas, jika terdapat $L>0$, sehingga setiap $a, b \in X$ berlaku

$$
\|T(a, b)\| \leq L\|a, b\| .
$$

Contoh 1. Diberikan sebarang lapangan bernilai non-Archimedean $(\mathbb{K},||$.$) , dan \left(\mathbb{K}^{2},\|\|.\right)$ ruang bernorma non-Archimedean, maka $\mathbb{K}^{2}$ merupakan ruang bernorma-2 non-Archimedean dengan

Akibatnya, operator $T: \mathbb{K}^{2} \times \mathbb{K}^{2} \rightarrow \mathbb{K}^{2}$, dengan

$$
\|x, y\|=\left\{\begin{array}{c}
\|x\|\|y\| ; x, y \text { bebas linear, } \\
0 ; x, y \text { tak bebas linear. }
\end{array}\right.
$$

Diperhatikan bahwa,

$$
T(x, y)=T\left(\left(x_{1}, x_{2}\right),\left(y_{1}, y_{2}\right)\right)=\left(x_{1} y_{1}, x_{2} y_{2}\right)=x y \text {. }
$$

dan

$$
\begin{aligned}
F(x+u, y+v)= & (x+u)(y+v)=x y+x v+u y+u v, \\
& F(\alpha x, \beta y)=\alpha \beta x y,
\end{aligned}
$$

Dengan demikian terbukti bahwa $T$ operator linear-2.

$$
\|T(x, y)\|=\|x y\|
$$

Contoh 2. Operator $T_{\mathbb{Q}}=\mathbb{Q}^{2} \times \mathbb{Q}^{2} \rightarrow \mathbb{Q}$ dengan

$$
T_{\mathbb{Q}}(x, y)=\operatorname{det}\left(\begin{array}{ll}
x_{1} & y_{1} \\
x_{2} & y_{2}
\end{array}\right) \text {. }
$$

Dengan norma non-Archimedean pada $\mathbb{Q}$ didefinisikan sebagai nilai mutlak p-adic dan norma-2 nonArchimedean pada $\mathbb{Q}$ didefinisikan dengan

maka $T_{\mathbb{Q}}$ merupakan operator linear-2 terbatas.

$$
\|x, y\|=\left|\operatorname{det}\left(\begin{array}{ll}
x_{1} & y_{1} \\
x_{2} & y_{2}
\end{array}\right)\right|_{p}
$$


Selanjutnya, jika $T: X^{2} \rightarrow Y$ merupakan operator linear-2 terbatas dan $x, y \in X$ saling tak bebas linear maka dapat dimengerti bahwa $T(x, y)=0$. Dibentuk

$$
B\left(X^{2}, Y\right)=\left\{T: X^{2} \rightarrow Y: \text { linear }-2 \text { terbatas }\right\} .
$$

Akan ditunjukan bahwa $B\left(X^{2}, Y\right)$ merupakan ruang bernorma non-Archimedean. Namun sebelumnya, ditunjukan bahwa $B\left(X^{2}, Y\right)$ merupakan ruang linear.

Lemma 1. $B\left(X^{2}, Y\right)$ merupakan ruang linear.

Bukti: Diambil sebarang $F, G \in B\left(X^{2}, Y\right)$ dan $\alpha, \beta, \gamma \in \mathbb{K}$. Diperhatikan bahwa, untuk setiap $a, b, c, d \in$ $X$, berlaku

$$
\begin{aligned}
(\alpha F+G)(a+c, b+d)= & \alpha F(a+c, b+d)+G(a+c, b+d) \\
= & \alpha F(a, b)+G(a, b)+\alpha F(a, d)+G(a, d) \\
& +\alpha F(c, b)+G(c, b)+\alpha F(c, d)+G(c, d) \\
= & (\alpha F+G)(a, b)+(\alpha F+G)(a, d) \\
& +(\alpha F+G)(c, b)+(\alpha F+G)(c, d), \\
(\alpha F+G)(\beta a, \gamma b)= & \alpha F(\beta a, \gamma b)+G(\beta a, \gamma b) \\
= & \alpha \beta \gamma F(a, b)+\beta \gamma G(a, b) \\
= & \beta \gamma(\alpha F+G)(a, b),
\end{aligned}
$$

dan terdapat $L_{1}, L_{2}>0$, sehingga untuk setiap $a, b \in X$, berlaku

$$
\begin{aligned}
\|(\alpha F+G)(x, y)\| & =\|\alpha F(x, y)+G(x, y)\| \\
& \leq \operatorname{maks}\{\|\alpha F(x, y)\|,\|G(x, y)\|\} \\
& \leq\|\alpha F(x, y)\|+\|G(x, y)\| \\
& \leq|\alpha|\|F(x, y)\|+\|G(x, y)\| \\
& \leq|\alpha| L_{1}\|x, y\|+L_{2}\|x, y\| \\
& =\left(|\alpha| L_{1}+L_{2}\right)\|x, y\| .
\end{aligned}
$$

Dengan demikian terbukti bahwa $B\left(X^{2}, Y\right)$ ruang linear

Berikut di konstruksikan suatu fungsi yang merupakan norma non-Archimedean pada $B\left(X^{2}, Y\right)$. Namun sebelumnya, diperhatikan bahwa, jika untuk setiap $x, y \in X$ yang saling bebas linear maka $\|x, y\| \neq 0$. Akibatnya jika $T: X^{2} \rightarrow Y$ merupakan operator linear-2 terbatas, maka terdapat $L>0$, sehingga untuk setiap $x, y \in X$ yang saling bebas linear, maka

Dengan demikian, himpunan

$$
\frac{\|F(x, y)\|}{\|x, y\|} \leq \frac{L\|x, y\|}{\|x, y\|}=L \text {. }
$$

$$
H=\left\{\frac{\|F(x, y)\|}{\|x, y\|}: x, y \in X,\|x, y\| \neq 0\right\} \subset \mathbb{R}
$$

terbatas. Akibatnya bedasarkan sifat kelengkapan pada $\mathbb{R}$, maka $H$ memiliki supremum dan infimum.

Teorema 1. Ruang $B\left(X^{2}, Y\right)$ merupakan ruang bernorma non-Archimedean dengan norma nonArchimedean didefinisikan dengan,

$$
\|F\|=\sup \left\{\frac{\|F(x, y)\|}{\|x, y\|}: x, y \in X,\|x, y\| \neq 0\right\} .
$$

Bukti: Diperhatikan bahwa jika $\|F\|=0$, maka $\frac{\|F(x, y)\|}{\|x, y\|}=0$, untuk setiap $\|x, y\| \neq 0$. Dengan demikian diperoleh $\|F(x, y)\|=0$, untuk setiap $\|x, y\| \neq 0$. Akibatnya $F(x, y)=0$, untuk setiap $x, y \in X$, yang tak bebas linear. Karena $F$ linear-2 dan terbatas, maka diperoleh $F=0$. Sebaliknya, jika diketahui $F=0$, maka $\frac{\|F(x, y)\|}{\|x, y\|}=0$, untuk setiap $x, y \in X,\|x, y\| \neq 0$, akibatnya 


$$
\|F\|=\sup \left\{\frac{\|F(x, y)\|}{\|x, y\|}: x, y \in X,\|x, y\| \neq 0\right\}=0 .
$$

Untuk sebarang $F \in B\left(X^{2}, Y\right)$, dapat dimengerti bahwa $\|F\|=\|-F\|$. Selanjutnya, untuk setiap $F, G \in B\left(X^{2}, Y\right)$ dan $x, y \in X$ diperoleh

$$
\begin{aligned}
\|F+G\|= & \sup \left\{\frac{\|(F+G)(x, y)\|}{\|x, y\|}: x, y \in X,\|x, y\| \neq 0\right\} \\
\leq & \sup \left\{\frac{\|F(x, y)\|}{\|x, y\|}: x, y \in X,\|x, y\| \neq 0\right\} \\
& +\sup \left\{\frac{\|G(x, y)\|}{\|x, y\|}: x, y \in X,\|x, y\| \neq 0\right\} \\
= & \|F\|+\|G\| .
\end{aligned}
$$

Dengan demikian terbukti $B\left(X^{2}, Y\right)$ ruang bernorma non-Archimedean.

Selanjutnya, berikut akan diberikan beberapa ekuivalensi dari norma non-Archimedean pada $B\left(X^{2}, Y\right)$. Namun sebelumnya, diberikan lemma berikut:

Lemma 2. Operator linear-2 $T: X^{2} \rightarrow Y$ terbatas jika dan hanya jika terdapat $L>0$ sehingga,

$$
\|T(x, y)-T(u, v)\| \leq \operatorname{Laks}\{\|x-u, y\|,\|u, y-v\|\}
$$

atau

$$
\|T(x, y)-T(u, v)\| \leq L \operatorname{maks}\{\|x-u, v\|,\|x, y-v\|\},
$$

untuk setiap $x, y, u, v \in X$.

Bukti: Diperhatikan bahwa jika $T$ operator linear-2 terbatas maka terdapat $L>0$, sehingga untuk setiap $x, y, u, v \in X$, berlaku

$$
\begin{aligned}
\|T(x, y)-T(u, v)\| & =\|T(x, y)-T(u, y)+T(u, y)-T(u, v)\| \\
& =\|T(x, y)+T(-u, y)+T(u, y)+T(u,-v)\| \\
& \leq\|T(x-u, y)+T(u, y-v)\| \\
& \leq \operatorname{maks}\{\|T(x-u, y)\|,\|T(u, y-v)\|\} \\
& \leq \operatorname{Lmaks}\{\|x-u, y\|,\|u, y-v\|\},
\end{aligned}
$$

atau

$$
\begin{aligned}
\|T(x, y)-T(u, v)\| & =\|T(x, y)-T(x, v)+T(x, v)-T(u, v)\| \\
& \leq\|T(x, y)+T(x,-v)+T(x, v)+T(-u, v)\| \\
& \leq\|T(x, y-v)+T(x-u, v)\| \\
& \leq L \operatorname{maks}\{\|x-u, v\|,\|x, y-v\|\} .
\end{aligned}
$$

Sebaliknya, cukup diambil $u=v=0$.

Teorema 2. Untuk setiap $F \in B\left(X^{2}, Y\right)$ berlaku

$$
\begin{aligned}
\|F\| & =\sup \{\|F(x, y)\|: x, y \in X,\|x, y\|=1\} \\
& =\inf \{k:\|F(x, y)\| \leq k\|x, y\|, \forall x, y \in X\} \\
& =\sup \{\|F(x, y)\|: x, y \in X,\|x, y\| \leq 1\} \\
& =\inf \{k:\|T(x, y)-T(u, v)\| \leq k \operatorname{maks}\{\|x-u, y\|,\|u, y-v\|\}, \forall x, y, u, v \in X\} \\
& =\inf \{k:\|T(x, y)-T(u, v)\| \leq k \operatorname{maks}\{\|x-u, v\|,\|x, y-v\|\}, \forall x, y, u, v \in X\} .
\end{aligned}
$$

Bukti: Untuk setiap $x, y \in X$, dengan $\|x, y\| \neq 0$, dimisalkan $\alpha=\sqrt{\|x, y\|} \neq 0$, dan $u=\frac{x}{\alpha}$ dan $v=\frac{y}{\alpha^{\prime}}$ akibatnya,

Karena $F$ linear-2, maka

$$
\|u, v\|=\left\|\frac{x}{\alpha}, \frac{y}{\alpha}\right\|=\frac{1}{\alpha^{2}}\|x, y\|=1 .
$$


Selanjutnya, dibentuk

$$
\begin{aligned}
\|F\| & =\sup \left\{\frac{\|F(x, y)\|}{\|x, y\|}: x, y \in X,\|x, y\| \neq 0\right\} \\
& =\sup \left\{\frac{\|F(x, y)\|}{\sqrt{\|x, y\|} \sqrt{\|x, y\|}}: x, y \in X,\|x, y\| \neq 0\right\} \\
& =\sup \left\{\left\|F\left(\frac{x}{\sqrt{\|x, y\|}}, \frac{y}{\sqrt{\|x, y\|}}\right)\right\|: x, y \in X,\|x, y\| \neq 0\right\} \\
& =\sup \{\|F(u, v)\|: u, v \in X,\|u, v\|=1\} .
\end{aligned}
$$

$$
K=\{k:\|F(x, y)\| \leq k\|x, y\|, \forall x, y \in X\} .
$$

Dapat dimengerti bahwa $\|F\| \in K$, akibatnya $\inf K \leq\|F\|$. Di sisi lain untuk setiap $k \in K$, dengan $x, y \in X$ yang saling tak bebas linear maka

Akibatnya,

$$
\frac{\|F(x, y)\|}{\|x, y\|} \leq k
$$

Dengan demikian $\|F\|=\inf K$.

$$
\sup \left\{\frac{\|F(x, y)\|}{\|x, y\|}: x, y \in X,\|x, y\| \neq 0\right\} \leq k .
$$

Diperhatikan bahwa, untuk setiap $x, y \in X$ dengan $\|x, y\| \leq 1$, diperoleh

$$
\|F(x, y)\| \leq\|F\|\|x, y\| \leq\|F\| \text {. }
$$

Akibatnya,

$$
\sup \{\|F(x, y)\|: x, y \in X,\|x, y\| \leq 1\} \leq\|F\| .
$$

Sebaliknya, karena $\|F\|=\sup \{\|F(u, v)\|: u, v \in X,\|u, v\|=1\}$, akibatnya

$$
\|F\| \leq \sup \{\|F(x, y)\|: x, y \in X,\|x, y\| \leq 1\} \text {. }
$$

Dengan demikian $\|F\|=\sup \{\|F(x, y)\|: x, y \in X,\|x, y\| \leq 1$.

Lebih lanjut, dibentuk

$$
H=\{k:\|T(x, y)-T(u, v)\| \leq k \operatorname{maks}\{\|x-u, y\|,\|u, y-v\|\}, \forall x, y, u, v \in X\} .
$$

Dapat dimengerti bahwa $K$ merupakan himpunan bagian dari $H$. Akibatnya, $\inf H \leq \inf K=\|F\|$.

Di sisi lain, untuk setiap $k \in H$, diperoleh

$$
\frac{\|F(x, y)\|}{\|x, y\|} \leq k,
$$

untuk setiap $x, y, u, v \in X$ dengan $\|x, y\| \neq 0, u=v=0$. Akibatnya $\|F\| \leq k$, sehingga $\|F\| \leq \inf H$. Dengan demikian $\|F\|=\inf H$. Pada persamaan yag terakhir dapat dibuktikan dengan cara sejalan.

Selanjutnya akan diberikan kondisi agar $B\left(X^{2}, Y\right)$ merupakan ruang Banach non-Archimedean.

Lemma 3. Diberikan barisan $\left(F_{n}\right)$ di dalam $B\left(X^{2}, Y\right)$. Jika untuk setiap $x, y \in X$, barisan $\left(F_{n}(x, y)\right)$ di dalam $Y$, dan konvergen ke $F(x, y)$ maka barisan $\left(\left\|F_{n}(x, y)\right\|\right)$ konvergen ke $(\|F(x, y)\|)$.

Bukti. Karena barisan $\left(F_{n}(x, y)\right)$ konvergen ke $F(x, y)$, akibatnya untuk setiap $\epsilon>0$, terdapat $n_{0} \in$ $\mathbb{N}$, sehingga untuk setiap $n \in \mathbb{N}$, dengan $n \geq n_{0}$ berlaku

Karena

$$
\left\|F_{n}(x, y)-F(x, y)\right\|<\epsilon .
$$

Terbukti barisan $\left(\left\|F_{n}(x, y)\right\|\right)$ konvergen ke $(\|F(x, y)\|)$

Lemma 4. Jika $\left(F_{n}\right)$ barisan Cauchy di dalam $B\left(X^{2}, Y\right)$, maka $\left(\left\|F_{n}\right\|\right)$ merupakan barisan Cauchy di dalam $\mathbb{R}$. 
Bukti. Karena $\left(F_{n}\right)$ barisan Cauchy di dalam $B\left(X^{2}, Y\right)$, maka untuk setiap $\epsilon>0$, terdapat $n_{0} \in \mathbb{N}$, sehingga setiap $n, m \in \mathbb{N}$, dengan $n, m \geq n_{0}$ berlaku

$$
\left\|F_{n}\right\|-\|F\| \mid \leq\left\|F_{n}-F_{m}\right\|<\epsilon .
$$

Dengan demikian terbukti bahwa $\left(\left\|F_{n}\right\|\right)$ merupakan barisan Cauchy di dalam $\mathbb{R}$.

Teorema 3. Jika $Y$ ruang Banach non-Archimedean, maka $B\left(X^{2}, Y\right)$ merupakan ruang Baach nonArchimedean.

Bukti. Diambil sebarang barisan Cauchy $\left(F_{n}\right)$ didalam $B\left(X^{2}, Y\right)$. Akibatnya, untuk setiap $\epsilon>0$, terdapat $n_{0} \in \mathbb{N}$, sehingga untuk setiap $n, m \in \mathbb{N}$ dengan $n, m \geq n_{0}$ berlaku

Dengan demikian, untuk setiap $x, y \in X$, diperoleh

$$
\left\|F_{n}-F_{m}\right\|<\frac{\epsilon}{2}
$$

$$
\begin{aligned}
\left\|F_{n}(x, y)-F_{m}(x, y)\right\| & =\left\|\left(F_{n}-F_{m}\right)(x, y)\right\| \\
& \leq\left\|F_{n}-F_{m}\right\|\|x, y\| \\
& <\frac{\|x, y\| \epsilon}{2} .
\end{aligned}
$$

Akibatnya, untuk setiap $x, y \in X$, barisan $\left(F_{n}(x, y)\right)$ merupakan barisan Cauchy di dalam $Y$. Selanjutnya, karena $Y$ merupakan ruang Banach non-Archimedean, maka terdapat $F(x, y) \in Y$, sehingga

$$
F(x, y)=\lim _{n \rightarrow \infty} F_{n}(x, y)
$$

Oleh karenanya, untuk setiap $\epsilon>0$, terdapat $N \in \mathbb{N}$, sehingga untuk setiap $n \in \mathbb{N}$, dengan $n \geq N$ berlaku

$$
\left\|F_{n}(x, y)-F(x, y)\right\|<\frac{\|x, y\| \epsilon}{2} .
$$

Selanjutnya, diperhatikan bahwa untuk setiap $x, y, u, v \in X$ dan $\alpha, \beta \in \mathbb{K}$, berlaku

$$
\begin{aligned}
F(x+u, y+v) & =\lim _{n \rightarrow \infty} F_{n}(x+u, y+v) \\
& =\lim _{n \rightarrow \infty} F_{n}(x, y)+\lim _{n \rightarrow \infty} F_{n}(x, v)+\lim _{n \rightarrow \infty} F_{n}(u, y)+\lim _{n \rightarrow \infty} F_{n}(u, v) \\
& =F(x, y)+F(x, v)+F(u, y)+F(u, v),
\end{aligned}
$$

dan

$$
\begin{aligned}
F(\alpha x, \beta y) & =\lim _{n \rightarrow \infty} F_{n}(\alpha x, \beta y) \\
& =\alpha \beta \lim _{n \rightarrow \infty} F_{n}(x, y) \\
& =\alpha \beta F(x, y) .
\end{aligned}
$$

Dengan demikian $F$ merupakan operator linear-2. Berdasarkan Lemma 4, karena $\left(\left\|F_{n}\right\|\right)$ merupakan barisan Cauchy di dalam $\mathbb{R}$, maka $\left(\left\|F_{n}\right\|\right)$ terbatas. Artinya, terdapat $L>0$, sedemikian sehingga untuk setiap $x, y \in X$ berlaku

$$
\begin{aligned}
\|F(x, y)\| & =\left\|\lim _{n \rightarrow \infty} F_{n}(x, y)\right\| \\
& =\lim _{n \rightarrow \infty}\left\|F_{n}(x, y)\right\| \\
& \leq \lim _{n \rightarrow \infty}\left\|F_{n}\right\|\|x, y\| \\
& \leq \lim _{n \rightarrow \infty} L\|x, y\| \\
& \leq L\|x, y\| .
\end{aligned}
$$

Akibatnya, diperoleh bahwa $F \in B\left(X^{2}, Y\right)$. Selanjutnya, diperhatikan saat $\|x, y\| \neq 0$, diperoleh

$$
\begin{aligned}
\left\|F_{n}(x, y)-F(x, y)\right\| & =\left\|F_{n}(x, y)-F_{m}(x, y)+F_{m}(x, y)-F(x, y)\right\| \\
& \leq \operatorname{maks}\left\{\left\|F_{n}(x, y)-F_{m}(x, y)\right\|,\left\|F_{m}(x, y)-F(x, y)\right\|\right\}
\end{aligned}
$$




$$
<\frac{\|x, y\| \epsilon}{2}<\|x, y\| \epsilon .
$$

Disisi lain saat $\|x, y\|=0$, maka $x, y$ saling tak bebas linear. Karena $F_{n}, F \in B\left(X^{2}, Y\right)$ maka $F_{n}(x, y)=0=F(x, y)$. Dengan demikian, untuk setiap $x, y \in X$, berlaku

Dengan demikian, karena

$$
\left\|F_{n}(x, y)-F(x, y)\right\| \leq\|x, y\| \epsilon \text {. }
$$

diperoleh

$$
\left\|F_{n}(x, y)-F(x, y)\right\| \leq\left\|F_{n}-F\right\|\|x, y\|
$$

$$
\left\|F_{n}-F\right\|<\epsilon, \forall n \geq N .
$$

Akibatnya, terbukti bahwa setiap barisan Cauchy $\left(F_{n}\right) \in B\left(X^{2}, Y\right)$ konvergen ke $F \in B\left(X^{2}, Y\right)$. Dengan kata lain terbukti $B\left(X^{2}, Y\right)$ lengkap, atau $B\left(X^{2}, Y\right)$ merupakan ruang Banach non-Archimedean.

\section{Kesimpulan}

Dapat dibentuk suatu norma non-Archimedean pad $B\left(X^{2}, Y\right)$ sedemikian sehingga $B\left(X^{2}, Y\right)$ merupakan ruang Banach non-Archimedean, dengan syarat $Y$ merupakan ruang Banach non-Archimedean.

\section{Ucapan Terimakasih}

Ucapan terimakasih penulis haturkan kepada Prodi Pendidikan Matematika UAD yang telah memberikan dukungan untuk melakukan penelitian ini.

\section{Referensi}

[1] S. Gahler. 1964. Lineare 2-normierte raume. Math. Nachr, 28: 1-43.

[2] H. Gunawan and Mashadi. 2001. On n-Normed Spaces. Int. J. Math. Sci., 27: 631-639.

[3] S.M. Gozali, H. Gunawan, and O. Neswan. 2010. On n-Norms and Bounded n-Linear Functionals in a Hilbert Spaces. Ann. Funct. Anali. 1: 72-79.

[4] Agus L. Soenjaya. 2012. On n-Bounded and n-Continuous Operator in n-Normed Spaces. J. Indones. Math. Soc. Vol. 18, No. 1: 45-56.

[5] Hahng-Yun Chu, Se-Hyun Ku, and Dong Seung Kang. 2008. Characterizations on 2-Isometries. Journal math. Anal. Appl. 340:641-628.

[6] R. W. Freese, Y. J. Cho. 2001. Geometry of Linear 2-Normed Spaces. Hauppauge, New-York, Nova Science Publisher Inc.

[7] A. F. Monna. 1943. Linear Functional Equations in Non-Archimedean Banach Spaces. Nederl. Akad. Wetensch. Verslagen. Afd. Natuurkunde, 52: 654-661.

[8] C. Perez-Garcia and W. H. Schikhof. 2010. Locally Convex Spaces Over Non-Archimedean Valued Fields. Cambridge, Cambridge University Press.

[9] Toka Diagana. 2009. Non-Archimedean Linear Operators and Applications. New York, Nova Science Publisher Inc.

[10] M. Amyari and Gh. Sadeghi. 2009. Mapping on Non-Archimedean Strictly 2-Convex 2-Normed Spaces. The 18 Seminar on Mathematical Analysis and its Applications, Tarbiat Moallem University: 57-60.

[11] Jaeyoo Choy and Se-Hyun Ku. 2009. Characterization on 2-isometries in Non-Archimedean 2-Normed Spaces. Journal of The Chungcheong Mathematical Society, Vol 22, No. 1: 65-71.

[12] Hahng-Yun Chu and Se-Hyun Ku. 2013. A Mazur-Ulam Theorem problem in non-Archimedean n-Normed Spaces. Jounal of Inequalities and Applications, 2013, 34: 1-10.

[13] A.C.M. Rooij. 1978. Non-Archimedean Functional Analysus. New York and Besel, Marcel Dekker Inc. 